\title{
Health-promoting substances and heavy metal content in tomatoes grown with different farming techniques
}

\author{
Filippo Rossi - Francesco Godani - Terenzio Bertuzzi • \\ Marco Trevisan · Federico Ferrari · Sergio Gatti
}

Published online: 6 May 2009

(C) Springer-Verlag 2009

Erratum to: Eur J Nutr (2008) 47:266-272

DOI 10.1007/s00394-008-0721-z

An error occurred in the article by Rossi et al. "Health promoting substances and heavy metal content in tomatoes grown with different farming techniques" published in the August 2008 issue of European Journal of Nutrition. On page 267 "Methods" section, "Samples" subsection the following phrase was omitted from the fertilizing technique of organic tomatoes "The same field where organic tomatoes were grown was previously cropped to Italian ryegrass, and this crop was fertilized with $100 \mathrm{tha}^{-1}$ of organic cattle slurry".

This should have read "The same field where organic tomatoes were grown was previously cropped to Italian ryegrass, and this crop was fertilized with $100 \mathrm{tha}^{-1}$ of organic cattle slurry. Organic tomatoes were fertilized with $30 \mathrm{t} \mathrm{ha}^{-1}$ of manure".

The online version of the original article can be found under doi:10.1007/s00394-008-0721-z.

F. Rossi $(\bowtie) \cdot$ T. Bertuzzi · S. Gatti

Istituto di Scienze degli Alimenti e della, Nutrizione,

Facoltà di Agraria, Università Cattolica del Sacro Cuore,

Via Emilia Parmense 84, 29100 Piacenza, Italy

e-mail: filippo.rossi@unicatt.it

F. Godani $\cdot$ S. Gatti

PAREN srl, Noceto (Parma), Italy

M. Trevisan · F. Ferrari

Istituto di Chimica Agraria ed Ambientale, Facoltà di Agraria,

Università Cattolica del Sacro Cuore, Piacenza, Italy 